\title{
A FIELD EVALUATION OF AIRBORNE TECHNIQUES FOR DETECTION OF UNEXPLODED ORDNANCE
}

\author{
W. E. Doll, P. Hamlett, J. Smyre, and D. Bell, Oak Ridge National Laboratory, MS 6038,
} P O Box 2008, Oak Ridge, TN, 37831-6038; J. E. Nyquist, Temple University, Philadelphia, PA; T. J. Gamey and J. S. Holladay, Aerodat Ltd, Mississauga, Ontapig, E EIVE
Canada

\begin{abstract}
United States Defense Department estimates indicate that as many as 11 million acres of government land in the U. S. may contain unexploded ordnance (UXO), with the cost of identifying and disposing of this material estimated at nearly $\$ 500$ billion. The size and character of the ordnance, types of interference, vegetation, geology, and topography vary from site to site. Because of size or composition, some ordnance is difficult to detect with any geophysical method, even under favorable soil and cultural interference conditions. For some sites, airborne methods may provide the most time and cost effective means for detection of UXO. Airborne methods offer lower risk to field crews from proximity to unstable ordnance, and less disturbance of sites that may be environmentally sensitive.
\end{abstract}

Data were acquired over a test site at Edwards AFB, CA using airborne magnetic, electromagnetic, multispectral and thermal sensors. Survey areas included sites where trenches might occur, and a test site in which we placed deactivated ordnance, ranging in size from small "bomblets" to large bombs. Magnetic data were then acquired with the Aerodat HM-3 system, which consists of three cesium magnetometers within booms extending to the front and sides of the helicopter, and mounted such that the helicopter can be flown within $3 \mathrm{~m}$ of the surface. Electromagnetic data were acquired with an Aerodat 5 frequency coplanar induction system, deployed as a sling load from a helicopter, with a sensor altitude of $15 \mathrm{~m}$. Surface data, acquired at selected sites, provide a comparison with airborne data. Multispectral and thermal data were acquired with a Daedelus AADS1268 system. Preliminary analysis of the test data demonstrate the value of airborne systems for UXO detection and provide insight into improvements that might make the systems even more effective

\section{BACKGROUND}

Many methods have been proposed for detection of UXO. Most methods require surface deployed instrumentation. Although these methods may have the greatest sensitivity, they suffer from high acquisition costs $(\$ 1,000$ to $\$ 20,000$ per acre, depending on site conditions), can be extremely time consuming, and may involve risk to personnel and damage to the environment. For instance, a recent surface survey at Edwards AFB required that the area be bulldozed before data acquisition because the vegetation, though sparse, interfered with walking paths. It is estimated that 11 million acres of government land in the United States may contain UXO, and the cost of identifying and disposing of this material is estimated at nearly $\$ 500$ billion. Significant cost savings will be achieved if it can be demonstrated that airborne methods can meet or approach the resolution of 


\section{DISCLAIMER}

This report was prepared as an account of work sponsored by an agency of the United States Government. Neither the United States Government nor any agency thereof, nor any of their employees, make any warranty, express or implied, or assumes any legal liability or responsibility for the accuracy, completeness, or usefulness of any information, apparatus, product, or process disclosed, or represents that its use would not infringe privately owned rights. Reference herein to any specific commercial product, process, or service by trade name, trademark, manufacturer, or otherwise does not necessarily constitute or imply its endorsement, recommendation, or favoring by the United States Government or any agency thereof. The views and opinions of authors expressed herein do not necessarily state or reflect those of the United States Government or any agency thereof. 


\section{DISCLAIMER}

Portions of this document may be illegible in electronic image products. Images are produced from the best available original document. 
surface systems.

Recent airborne surveys at Edwards AFB used systems and approaches that demonstrate the potential of airborne methods for detection of UXO. Airborne platforms are attractive for UXO investigations because of 1) their ability to cover a large area in a short period of time, 2) their promise as a much more cost-effective approach than surface measurement techniques, and 3) they do not disturb the surface, thus avoiding safety and environmental concerns and additional costs. Variation in acquisition and processing costs among the different sensors is broad. For example, magnetic and electromagnetic sensors require dense flight path spacing which results in high acquisition costs but low processing costs. By contrast, acquisition of spectral remote sensing data is relatively inexpensive, while processing is costly. Design of an optimal acquisition and processing strategy is essential to streamlining airborne reconnaissance methods for UXO detection.

\section{MAGNETIC SENSORS}

Most surface surveys for UXO include magnetometers among their sensors. Airborne methods are not used frequently for UXO detection because the signal falls off as the third power of the distance between the ordnance and the magnetometer, and it has not been possible to fly with magnetometers sufficiently close to the ground. The development of the Aerodat $\mathrm{HM}^{3}$ airborne system (Gamey and Mahler, 1999), in which the magnetometers can be flown within 3 meters of the ground, is the first step in development of airborne systems that can compete with surface magnetic systems in $\mathrm{UXO}$ detection. The $\mathrm{HM}^{3}$ system operates with three cesium vapor magnetometers attached to $6 \mathrm{~m}$ booms, extending from the front, port, and starboard sides of the helicopter. Data are acquired at $3 \mathrm{~m}$ nominal line spacing by interleaving flight lines. Noise effects are accommodated by using high sample rates with appropriate filters, by close monitoring of the pitch, yaw, and flight path of the helicopter, and by correcting the data on the basis of calibration data. These calibration data measure the effects of orientation when the helicopter is the only significant source of magnetic interference. Following real time signal processing to remove noise, the data are stored at 20 samples/sec (Gamey and Mahler, 1999).

Airborne data were acquired at a site that overlaps a site where surface geophysical data had previously been acquired by Earth Tech Inc. to detect ordnance waste trenches. The two data sets (Fig. 1) cover overlapping but not equal areas, as the area covered by surface instruments is smaller, and adjacent buildings prevented access to some portions of the site from the helicopter. Average altitude of the magnetometers for the airborne survey was 4-5 $\mathrm{m}$. Flightline noise is evident in the airborne data (oriented NE-SW). This is due in large part to small variations in altitude that cannot be completely removed by leveling or other available processing techniques when flying at such low altitudes.

Figure 1 shows that the same anomalies are detected from both surface and airborne systems, with airborne systems having resolution that is lower, but still acceptable for this application. It is important to note that bulldozing was required in advance of surface data acquisition, adding significant cost to the survey and insult to the environment. 


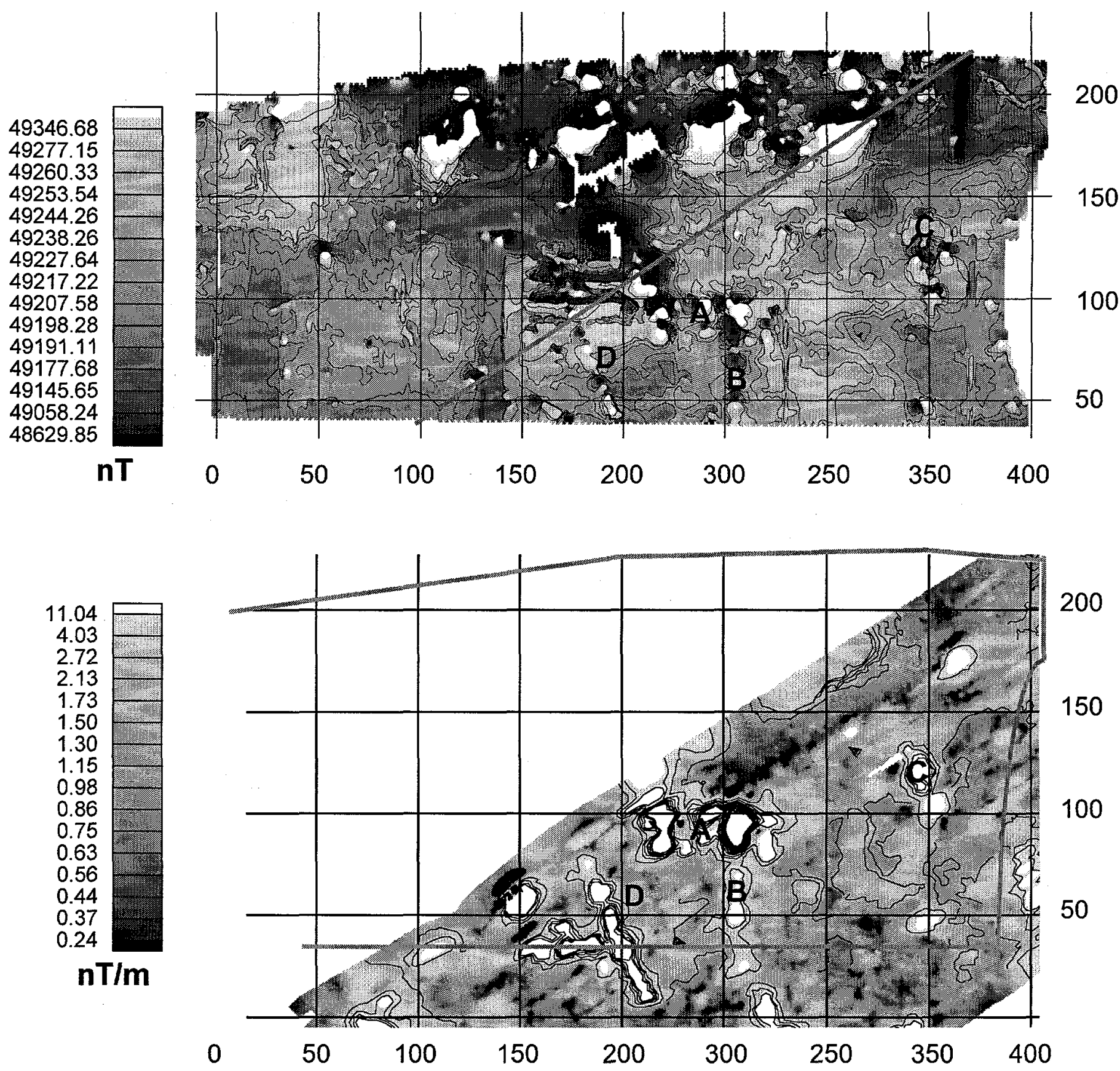

Figure 1. Comparison of surface total magnetic field map (top) to airborne analytic signal map (bottom) for a trench area at Edwards AFB, California. The grey lines indicate approximate boundaries of the companion maps. Anomalies are labeled with letters ("A", "B", "C", and "D") for ease of comparison. 
At another site, test data were acquired over deactivated ordnance arranged in two rows at $30 \mathrm{~m}$ spacing. The test area is thought to be free from man-made metallic debris, but this is not confirmed. The preliminary analytic signal map in Figure 2 demonstrates that current airborne systems are capable of detecting many types of UXO, some weighing only a few tens of kilograms (Fig. 2). The largest bombs (GB, GD, GK, GL, GM, and $\mathrm{GN}$ ) are easily detected. GA and GC are on the order of $100 \mathrm{~kg}$ net, and produce anomalies that are considerably larger than the noise. Anomalies GE, GF, GI, and GJ are in the 40-60 kg net weight range, and have anomalies that are comparable in amplitude with noise levels. We have not yet reviewed the iron content of these targets.

Interference from natural background ("geologic noise" as described in Doll and others, 1993; Nyquist and Doll, 1996) is important at Edwards AFB, presumably because of relatively high concentrations of magnetic minerals in the igneous rocks and alluvium. We believe that improvements in the acquisition systems and processing will lead to significant increases in the sensitivity of these systems.

\section{ELECTROMAGNETIC SENSORS}

Time domain electromagnetic instruments such as the EM-61 are commonly used for surface detection of ordnance. Currently available airborne instruments are designed for mineral detection and are flown at altitudes too great for detection of individual ordnance, typically 15 meters or higher. They do, however, provide important information about site geology that can be used to constrain magnetic interpretations. Electromagnetic instruments have the ability to detect non-magnetic ordnance, an attribute which is important for many types of ordnance, since much UXO is composed of non-magnetic metals, including alloys and aluminum.

Electromagnetic data were acquired at selected areas at Edwards AFB with an Aerodat 5frequency coplanar induction system, deployed as a sling load from a helicopter, with a sensor altitude of $15 \mathrm{~m}$. The targets at the selected sites were primarily waste trenches, although the system was also flown at our ordnance test area. As anticipated, the resolution of the data is too low to detect individual ordnance. Electromagnetic systems that can be flown at altitudes of less than $5 \mathrm{~m}$ will be required in order to field a viable airborne system for UXO detection.

\section{MULTISPECTRAL AND THERMAL IMAGING}

The Daedalus AADS1268 multispectral scanner is a spectrometer that digitally records solar reflectance and electromagnetic emissions from the earth's surface in 12 distinct spectral bands (Table 1) ranging from ultraviolet to thermal IR (including 2 thermal channels of the same wavelength but different gain settings). Data from each of the wavelengths may be analyzed jointly to identify a variety of surface and near-surface features.

For UXO detection, MSS data can be acquired using a helicopter platform at an altitude of 75-100 $\mathrm{m}$ above ground level. Acquisition is normally scheduled for two flight times, one during mid-morning and one at solar noon. Acquired data are post-processed to radiometrically correct and rectify the imagery. Computational analysis and data 


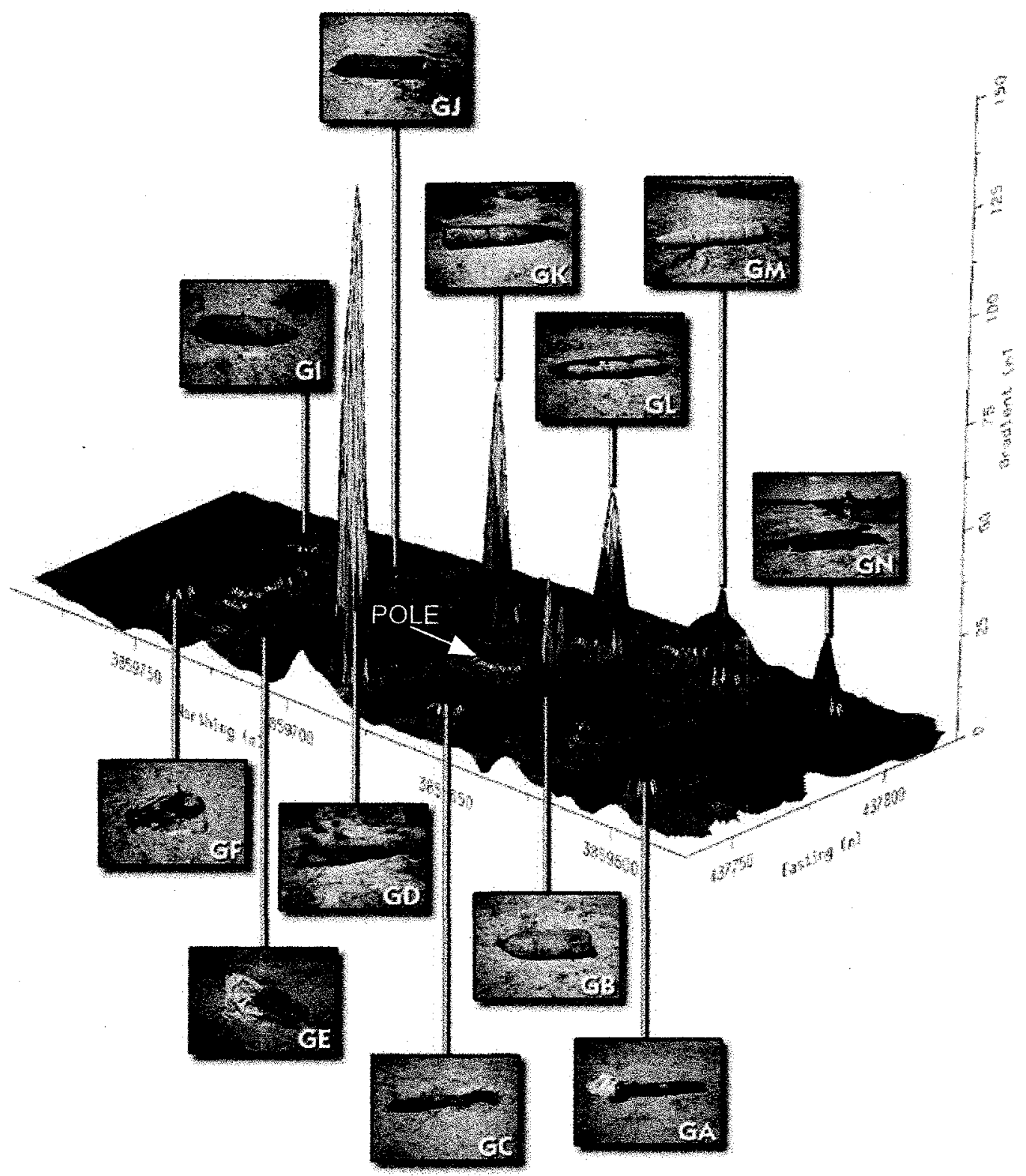

Figure 2. Analytic signal map for an ordnance test site at Edwards AFB. Individual pieces of ordnance were spaced about $30 \mathrm{~m}$ apart. The photographs show the ordnance that is associated with each anomaly. Broader anomalies with amplitudes that are similar to those from smaller pieces of UXO may be associated with geologic materials, except the one that is identified as being due to metals attached to a wooden pole ("POLE"). 
Table 1.

Spectral Sensitivity of the Daedalus AADS 1268 Multispectral Scanning System

\begin{tabular}{|c|c|c|}
\hline Channel Number & Wavelength (um) & Nominal Color \\
\hline 1 & $0.42-0.44$ & Violet/Blue \\
\hline 2 & $0.46-0.51$ & Blue/Green \\
\hline 3 & $0.52-0.59$ & Green/Yellow \\
\hline 4 & $0.59-0.62$ & Orange \\
\hline 5 & $0.62-0.67$ & Red \\
\hline 6 & $0.67-0.72$ & Near Infrared \\
\hline 7 & $0.73-0.85$ & Near Infrared \\
\hline 8 & $0.84-0.97$ & Near Infrared \\
\hline 9 & $1.59-1.79$ & Middle Infrared \\
\hline 10 & $2.10-2.40$ & Middle Infrared \\
\hline 11 & $8.28-10.67$ & Thermal Infrared \\
\hline 12 & $8.28-10.67$ & Thermal Infrared \\
\hline
\end{tabular}

interpretation are conducted using appropriate band ratios to identify areas with spectral signatures of materials such as rusted iron or ferrous materials, as well as vegetation indices that can act as indicators of past human activities such as bomb explosions and craters, buried hazardous wastes, and other cultural disturbances.

When flown during the pre-dawn hours, the Daedalus AADS1268 multispectral scanner can acquire thermal infrared imagery. Differential measures of surface temperature are recorded in thermal imagery and may be clues to subsurface materials, such as buried objects. Day/night heat differences can be documented and used to identify areas of cultural disturbances and metal on or near the surface. For UXO detection, thermal imagery is acquired using a helicopter platform at an altitude of $100 \mathrm{~m}$ above ground level. Acquisition occurs during the pre-dawn hours. The thermal infrared data are postprocessed to radiometrically correct and rectify the imagery.

Daytime multispectral and pre-dawn thermal data were acquired at Edwards sites with a Daedalus model AADS1268 multispectral scanner mounted in a BO-105 helicopter flying approximately $90 \mathrm{~m}$ above ground level (AGL). The resulting ground cell resolution was approximately $15-23 \mathrm{~cm}$. Various image processing techniques were applied to the daytime multispectral imagery to enhance it for detection of surface test ordnance (Fig. 3). 
a)

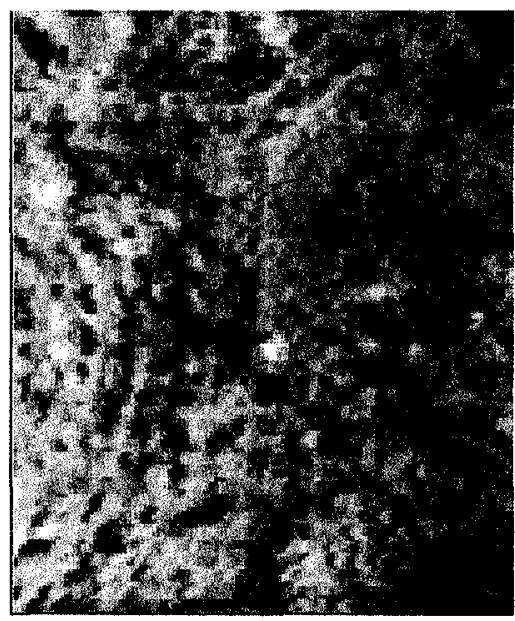

b)

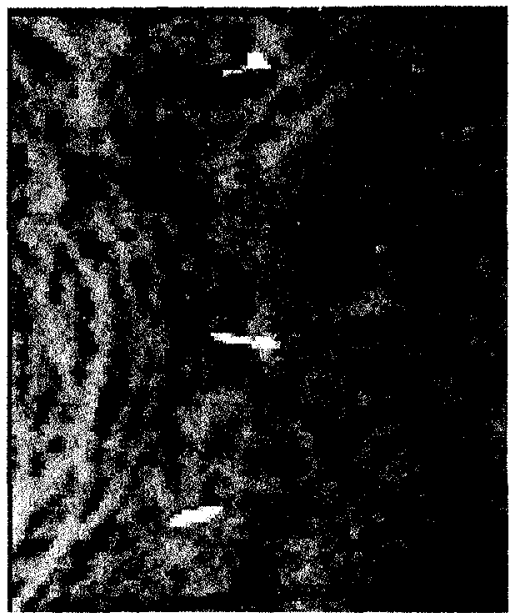

c)

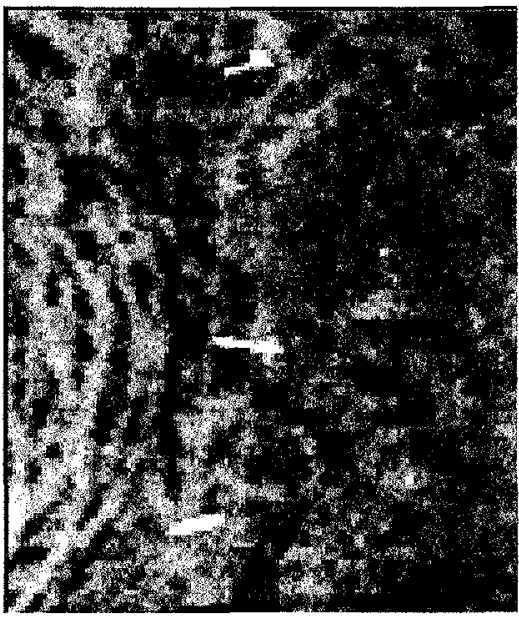

d)

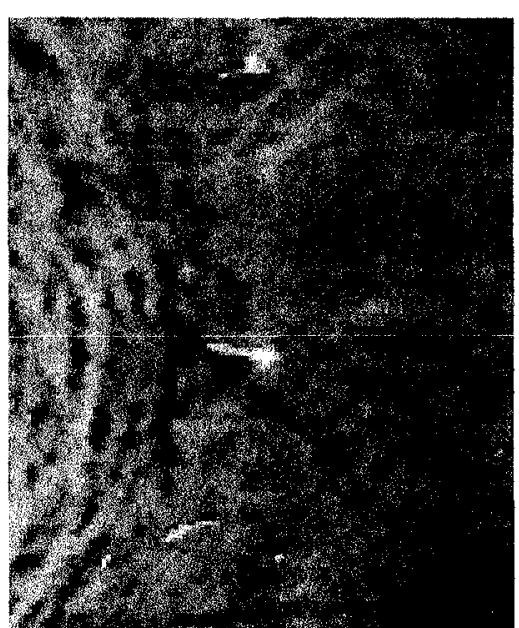

e)

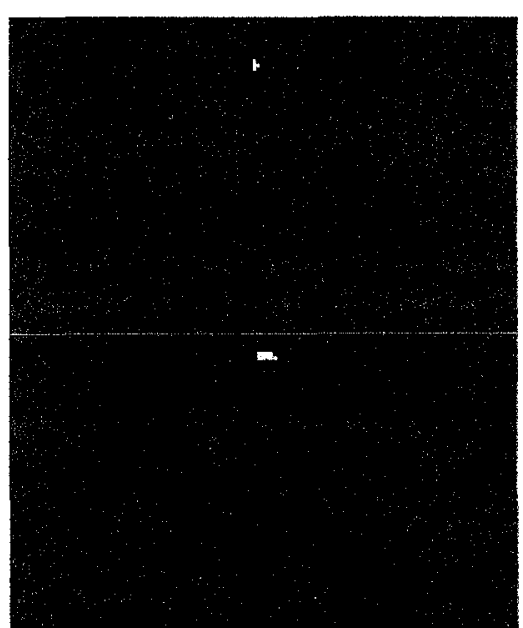

Figure 3. Multispectral and thermal imagery analysis techniques applied to the Edwards AFB test site. a) display of bands 5,3, and 2; b) combination of processes used to highlight the spectral signatures of UXO; c) Digital Numbers (Dns) of NDVI [(band $7+$ band 5)/(band 7 - band 5)] image are inverted (dark areas become bright, etc. to highlight bombs); d) Inverse NDVI displayed with band 7 and band 5 (RGB) ; and e) Isodata (Iterative Self-organizing Data Analysis Technique) clustering (process-based spectral distance patterns) performed on 15 band image (12 MSS bands plus NDVI, ferrous mineral index, and iron oxide index). 
These included the use of Normalized Difference Vegetation Index (NDVI) [(band $7+$ band 5)/(band 7 - band 5)], inverse NDVI, ferrous metal [band $9 /($ band $7+$ band 8$)$ ], and iron oxide (band 5/ band 2) indices to locate the presence of metallic or rusted metals and to minimize the selection of areas covered by vegetation and soil. Principal components analysis was used, and clustering techniques were applied to a 15-band image which merged the original 12-band multispectral imagery with NDVI, ferrous, and iron oxide indices. Other band ratios and spectral indices were also used, along with data re-scaling, spectral masks, and enhanced pseudo-color display to increase the visibility of detected ordnance in final imagery.

\section{DATA INTEGRATION AND FUSION}

A common approach to reducing geologic noise and other signal-to-noise problems is data fusion or integration (i.e. using data visualization tools or algorithms for combining multiple sensors in order to reduce the number of false positives). Several researchers have developed data fusion for UXO detection (e.g. Hollyer et al., 1997 and other papers from the UXO Forum '97) and for airborne detection of manmade structures (e.g. Johnson and Harben, 1997). In general, data fusion techniques have been developed at three levels: 1) a visual overlay approach (e.g. simply overlaying contours from magnetic or electromagnetic surveys on image data, such as MSS, thermal data, or aerial photographs);2) statistical methods, where thresholds are determined for each sensor, and then joint statistics are used to minimize the number of false positives; and 3) joint inversion methods. To date, we have applied the first level of fusion (visual overlay) to some of the Edwards AFB data, and have found it effective. More work needs to be done to integrate magnetic and electromagnetic data with image data, such as MSS data for UXO.

\section{CONCLUSIONS}

The preliminary results described here encourage continued development of airborne systems for UXO detection. The data point to improvements that are needed in airborne magnetic detection systems, and highlight the need for the parallel development of an airborne electromagnetic system, preferably one that could be flown simultaneously on the same platform, as with towed systems. The multispectral data demonstrate the effectiveness of that tool for surface ordnance. Other analyses of multispectral data might reveal indications of buried ordnance that could be used to augment geophysical measurements. Clearly, it is beneficial to combine evidence from as many sensors as possible to reduce noise, and ultimately to reduce the cost of UXO detection and removal.

Except for perhaps the largest ordnance, our results indicate that airborne geophysical systems should not be expected to be effective for areas where a dense vegetation canopy or rugged topography prevent acquisition from low altitudes. 


\section{ACKNOWLEDGEMENTS}

We would like to thank Robert Wood at Edwards AFB for providing funding and excellent logistical support for this project. Ed Bright (ORNL) assisted in processing some of the multispectral data. Amy King assisted in several logistical aspects and planning activities. Oak Ridge National Laboratory is managed by Lockheed Martin Energy Research Corp. for the U. S. Department of Energy under contract number DEAC05-96OR22464.

\section{REFERENCES}

Doll, W. E., J. E. Nyquist, and T. J. Gamey., 1993, Noise characterization in airborne environmental magnetic surveys, Abstract, EOS, Trans. Amer. Geophys. Union, October, 1993 (1993 Fall Meeting), p. 220.

Gamey, T. J. and R. Mahler, 1999, A comparison of towed and mounted helicopter magnetometer systems for UXO detection, Proceedings of the 1999 Symposium on the Application of Geophysics to Engineering and Environmental Problems (this volume).

Hollyer, G., L. Racic, and D. K. Butler, 1997, Enhancing geophysical data acquisition, quality control, processing, analysis and visualization for UXO detection, characterization, and discrimination, Proceedings, UXO Forum '97, p. 183-194.

Johnson, V. M., and P. E. Harben, 1997, Reducing uncertainty in the detection of underground facilities through data infusion, Jour. Envir. And Engr. Geophysics, v. 2, p. $151-163$.

Nyquist, J. E. and W. E. Doll, 1996, Analysis and interpretation of airborne geophysical data acquired over the Melton Valley waste area groupings and adjacent areas, Oak Ridge National Laboratory, Oak Ridge, Tennessee, Report ES/ER/TM-208, Oak Ridge Environmental Restoration Program, 113 pgs.

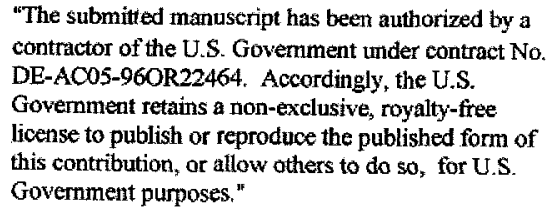

